\title{
SPHERICAL STANDING BURNING WAVE WITH EXTERNAL AUTOMATIC REACTIVITY CONTROL
}

\author{
Yu.Y. Leleko, V.V. Gann, A.V. Gann \\ National Science Center "Kharkov Institute of Physics and Technology", \\ Scientific and Technical Complex "Nuclear Fuel Cycle" \\ Center for Reactor Core Design, Kharkiv, Ukraine \\ E-mail: makswell.com@gmail.com
}

Neutron kinetics of a nuclear burning wave in moving incompressible neutron-multiplying medium in the presence of nuclear reactions is developed. A spherical reactor is considered, where fuel moves with acceleration to the center of the reactor at a velocity $\mathrm{V}(\mathrm{r})=\mathrm{V}_{\mathrm{R}}(\mathrm{R} / \mathrm{r})^{2}$, and the burning wave travels radially from the center to periphery. The fuel that came to the origin was unloaded from the reactor, and U-238 was loaded to the peripheral area at the same rate. Comparison of theoretical results with computer simulation using MCNPX code was performed.

\section{INTRODUCTION}

In this article, the theory of nuclear reactor on spherical standing burning wave is developed. The neutron kinetics of a nuclear burning wave in a moving neutronmultiplying medium in the presence of nuclear reactions was developed. Computer simulation of moving and standing spherical burning waves in a nuclear reactor was performed using MCNPX code [1].

The reactor core consists of four areas: the outer zone made of U-238, the breading zone where production of $\mathrm{Pu}-239$ takes place according to the scheme $\mathrm{U}-238+\mathrm{n}=\mathrm{U}-239 \rightarrow \mathrm{Np}-239 \rightarrow \mathrm{Pu}-239$, the inner region in which $\mathrm{Pu}-239$ is burning, and central area consists of burnt fuel. The fuel moves with acceleration from periphery to the center of the reactor. It is shown that in such a system a spherical standing wave travels radially from the center zone to periphery. The burning wave consists of two regions: the external - breading zone and the internal - burning area. Distributions of the neutron flux, the U-238, Np-239, and Pu-239 isotope concentrations and the specific power in the standing spherical burning wave are obtained in this paper. The conditions for existence of spherical standing burning waves are investigated. It is shown that an operation mode of the standing-wave reactor is characterized by two combinations of nuclear cross sections and single function defining the stability boundaries of the stem. Stability region of spherical waves was found to be broader then stability region of one-dimensional traveling burning waves in an infinite medium. A state diagram of such a reactor has been obtained.

Concept of the traveling wave nuclear reactor (TWR) is one of the brilliant ideas of 20-th century. It suggests using depleted uranium (or thorium) as fuel and promises to supply inexhaustible source of energy worldwide. This idea was proposed by S.M. Feinberg, realized in theory by L.P. Feoktistov [2] and developed in many publications (see bibliography in [3]), in which several ways of its practical implementation were suggested. One of the most promising designs of TWR is a fast reactor, which is able to work in maneuverable mode $[3,6]$. Mathematical modeling of TWR using MCNPX code was performed in [4, 7, 8].
Computer simulation of reactor on standing and traveling spherical burning wave has been carried out in present article. The computer model of the reactor using the MCNPX code is a ball of $2 \mathrm{~m}$ radius filled with uranium dioxide fuel. In the traveling spherical wave mode, nuclear burning begins in the central zone of the core enriched with uranium. When concentration of $\mathrm{Pu}-239$ in U-238 becomes high enough due to breeding mechanism according to the scheme U-238 $+\mathrm{n}=\mathrm{U}-239 \rightarrow$ $\mathrm{Np}-239 \rightarrow \mathrm{Pu}-239$, a spherical burning wave appears; then it breaks away from the ignition region and continuously moves to the edges of the core during $\sim 150$ years. In our model at a power of $240 \mathrm{MW}$, the burning wave velocity was $0.5 \mathrm{~cm} /$ year. The mode of a standing spherical burning wave (SWR) was achieved by selecting the values of fuel speed and reactor power. Radial distributions of neutron flux, power density and the concentrations of Pu-239 and U-238 in the spherical standing burning wave were obtained using MCNPX code. A comparison of theoretical results with the data of numerical simulation has been carried out. Possibility of using depleted uranium as a nuclear fuel in reactors on spherical burning wave is confirmed.

\section{NEUTRON KINETICS EQUATION IN MOVING NEUTRON-MULTIPLYING MEDIUM}

Let us consider nuclear burning wave in incompressible uranium-based medium, which moves to the center of the reactor at velocity $V(r)=V_{R}(R / r)^{2}$, where $V_{R}$ is speed of fuel at periphery of the reactor at $r=R$.

The simplest description of neutron kinetics and burning of nuclear fuel can be obtained using the coordinate system $\mathrm{x}$ ', $\mathrm{y}^{\prime}, \mathrm{z}$ ', in which the fuel is stationary:

$$
\begin{aligned}
& \frac{1}{\mathrm{v}} \frac{\partial \Psi}{\partial t}=\hat{D} \Psi+\left(v \Sigma_{f}-\Sigma_{a}\right) \Psi+S \\
& \frac{\partial n_{8}}{\partial t}=-n_{8} \sigma_{a 8} \Psi, \quad \frac{\partial \tilde{n}_{9}}{\partial t}=\sigma_{89} n_{8} \Psi-\frac{\tilde{n}_{9}}{\tau_{89}}, \\
& \frac{\partial n_{9}}{\partial t}=\frac{\tilde{n}_{9}}{\tau_{89}}-\sigma_{a 9} n_{9} \Psi, \frac{\partial n_{c}}{\partial t}=2 \sigma_{f 9} n_{9} \Psi,
\end{aligned}
$$


where $\Psi\left(\vec{r}^{\prime}, t\right)$ is neutron flow; v is speed of neutrons; $n_{8}\left(\vec{r}^{\prime}, t\right)$ is concentration of ${ }^{238} \mathrm{U} ; \tilde{n}_{9}\left(\vec{r}^{\prime}, t\right)$ is concentration of ${ }^{239} \mathrm{~Np} ; n_{9}\left(\vec{r}^{\prime}, t\right)$ is concentration of ${ }^{239} \mathrm{Pu}$; $n_{c}\left(\vec{r}^{\prime}, t\right)$ is concentration of fission products; $\hat{D}-$ neutron transport operator; $\Sigma_{f}=\sigma_{f 9} n_{9}-$ macroscopic cross-section of fission and $\Sigma_{a}=\sigma_{a 8} n_{8}+\sigma_{a 9} n_{9}+\sigma_{c} n_{c}$ - macroscopic neutron absorption cross section. $S$ term describing the reactor operating controls; $\sigma_{89}$ transmutation cross-section of ${ }^{238} \mathrm{U}$ to ${ }^{239} \mathrm{Pu} ; \tau_{89}-$ time of the decay in chain ${ }^{239} \mathrm{U} \rightarrow{ }^{239} \mathrm{~Np} \rightarrow{ }^{239} \mathrm{Pu} ; \sigma_{f 9}-$ fission cross-section of ${ }^{239} \mathrm{Pu} ; \mathrm{v}$ - the number of fission neutrons; $\sigma_{a 8}$ and $\sigma_{a 9}$ - neutron absorption crosssections for nuclei ${ }^{238} \mathrm{U}$ and ${ }^{239} \mathrm{Pu} ; \sigma_{c}$ is neutron absorption cross-section for fission products. To simplify we put $\sigma_{a 8}=\sigma_{a 9}=\sigma_{a}$.

Boundary conditions have to be added to Eqs. (1) and (2):

$$
\begin{gathered}
\Psi(\infty, t)=0, \Psi^{\prime}(0, t)=0, n_{9}(\infty, t)=0, \\
\tilde{n}_{9}(\infty, t)=0, n_{\mathrm{c}}(\infty, t)=0, n_{8}(\infty, t)=n_{8}(0) .
\end{gathered}
$$

We need to find a time-independent solution of equations (1) in the form of a spherical standing wave $\Psi(r), n_{8}(r), n_{9}(r)$. Consider the movement of fuel materials rather slow: $\tau_{89} V<<L$, where $L$ is the characteristic size of the burning region, then Eqs. (1), (2) can be interpreted as quasi-stationary $(\mathrm{v}=\infty)$. The operator $\hat{D}$ we choose in diffusion approximation.

The boundary conditions (3) look as follows:

$$
\begin{gathered}
\Psi(\infty)=0, \Psi^{\prime}(0)=0, n_{9}(\infty)=0, \\
n_{\mathrm{c}}(\infty)=0, n_{8}(\infty)=n_{0} .
\end{gathered}
$$

\section{THEORY OF SPHERICAL NUCLEAR BURNING WAVE}

\section{Equation for fluence}

Now, instead of the $r$ coordinate we will introduce a new variable

$$
\varphi(r)=\sigma_{a} \int_{r}^{\infty} \frac{\Psi\left(r^{\prime}\right)}{V\left(r^{\prime}\right)} d r^{\prime}=\frac{\sigma_{a}}{V_{R} R^{2}} \int_{r}^{\infty} \Psi\left(r^{\prime}\right) r^{\prime 2} d r^{\prime}
$$

which is proportional to fluence $F(x)$ and ranges from 0 to a maximum value of $\varphi_{0}=\sigma_{a} F_{\max }$. Let us choose the function $S(x)$ describing the automatic control on excess reactivity $\rho$ as: $S=-\rho v \Sigma_{f} \Psi$. After these changes Eqs. (1) and (2) become:

$$
\begin{aligned}
& \frac{D \sigma_{a}^{2}}{2 V_{R}^{2} R^{4}} \frac{\partial}{\partial \varphi}\left(r^{4} \frac{\partial \Psi^{2}}{\partial \varphi}\right)+v(1-\rho) \Sigma_{f}-\Sigma_{a}=0 \\
& \frac{d n_{8}}{d \varphi}=-n_{8}
\end{aligned}
$$

$\frac{d n_{9}}{d \varphi}=n_{8} \sigma_{89} / \sigma_{a}-n_{9}$

$\frac{d n_{c}}{d \varphi}=2 n_{9} \sigma_{f} / \sigma_{a}$,

$P=4 \pi V_{R} Q R^{2} / \sigma_{a} \int \Sigma_{f} d \varphi$,

$\Sigma_{f}=\sigma_{f} n_{9}$,

$\Sigma_{a}=\sigma_{a}\left(n_{8}+n_{9}\right)+\sigma_{c} n_{c}$,

where $Q$ is nuclei ${ }^{239} \mathrm{Pu}$ fission energy release.

The boundary conditions (4) for the functions $\Psi(\varphi)$, $n_{8}(\varphi), \tilde{n}_{9}(\varphi), n_{9}(\varphi)$ look as follows:

$\Psi(0)=0 ; \Psi^{\prime}\left(\varphi_{0}\right)=0 ; n_{9}(0)=0 ; n_{c}(0)=0 ; n_{8}(0)=n_{0}$,

(12)

where $\varphi_{0}=\varphi(0)$ is the maximum neutron fluence.

\section{Equation for neutron flux density}

Equations (6) - (8) can be solved:

$$
\begin{gathered}
n_{8}(\varphi)=n_{0} e^{-\varphi}, n_{9}(\varphi)=\sigma_{89} / \sigma_{a} n_{0} \varphi e^{-\varphi}, \\
n_{c}(\varphi)=2 \sigma_{f} \sigma_{89} / \sigma_{a}^{2} n_{0}\left[1-(1+\varphi) e^{-\varphi}\right],
\end{gathered}
$$

where $n_{0}$ is concentration of U-238 in the initial material, and equation (5) becomes:

$$
\begin{aligned}
& \frac{D \sigma_{a}}{2 n_{0} V_{R}^{2}} \frac{d}{d \varphi}\left(\frac{r^{4}(\varphi)}{R^{4}} \frac{d \Psi^{2}}{d \varphi}\right)=2 \beta+(1-2 \beta) e^{-\varphi}+ \\
& +\left(\frac{\sigma_{89}}{\sigma_{a}}-2 \beta\right) \varphi e^{-\varphi}-\frac{\sigma_{f} \sigma_{89}}{\sigma_{a}^{2}} v(1-\rho) \varphi e^{-\varphi},
\end{aligned}
$$

where $\beta=\sigma_{c} \sigma_{f} \sigma_{89} / \sigma_{a}^{3}$ is a parameter, which determines the speed of breeding in the system.

\section{System excess reactivity calculation}

Integrating equation (14) over $\varphi$ taking into account the boundary condition $\Psi(0)=0$, we obtain:

$$
\frac{D \sigma_{a}}{2 n_{0} V_{R}^{2}} \frac{r^{4}(\varphi)}{R^{4}} \frac{d \Psi^{2}}{d \varphi}=f(\varphi)
$$

where $\quad f(\varphi)=2 \beta \varphi-(1-2 \beta)\left(e^{-\varphi}-1\right)+$

$$
+\left[\frac{\sigma_{89}}{\sigma_{a}}-2 \beta-\frac{\sigma_{f} \sigma_{89}}{\sigma_{a}^{2}} v(1-\rho)\right]\left[1-(1+\varphi) e^{-\varphi}\right] .
$$

Substituting $\varphi=\varphi_{0}$ in (15) and using the boundary conditions (12), we obtain the equation for the system excess reactivity $\rho$ :

$$
f\left(\varphi_{0}\right)=0 .
$$

Solving Eq. (16) we obtain expression for excess reactivity, which is necessary for the existence of a stationary solution:

$$
\rho=\frac{\sigma_{a}^{2}}{\sigma_{f} \sigma_{89} \nu}\left(c-q_{0}\right)
$$


where

$$
\begin{aligned}
& q_{0}=\frac{2 \beta \varphi_{0}-(1-2 \beta)\left(e^{-\varphi_{0}}-1\right)}{1-\left(1+\varphi_{0}\right) e^{-\varphi_{0}}}, \text { and } \\
& c=\left(v \frac{\sigma_{f}}{\sigma_{a}}-1\right) \frac{\sigma_{89}}{\sigma_{a}}+2 \beta .
\end{aligned}
$$

Eq. (17) and (18) relate excess reactivity $\rho$ to the maximum fluence in unloaded fuel $\varphi_{0}$. This value lies in the range $0 \leq \varphi_{0} \leq \chi$, where $\chi$ is the maximum fluence in the flat burning wave [4] (Eq. (19) and Fig. 1):

$\beta=\frac{\left(e^{-\chi}-1\right)^{2}-\chi^{2} e^{-\chi}}{\chi^{2}\left[(1+\chi) e^{-\chi}-1\right]+2\left(\chi+e^{-\chi}-1\right)^{2}}$.

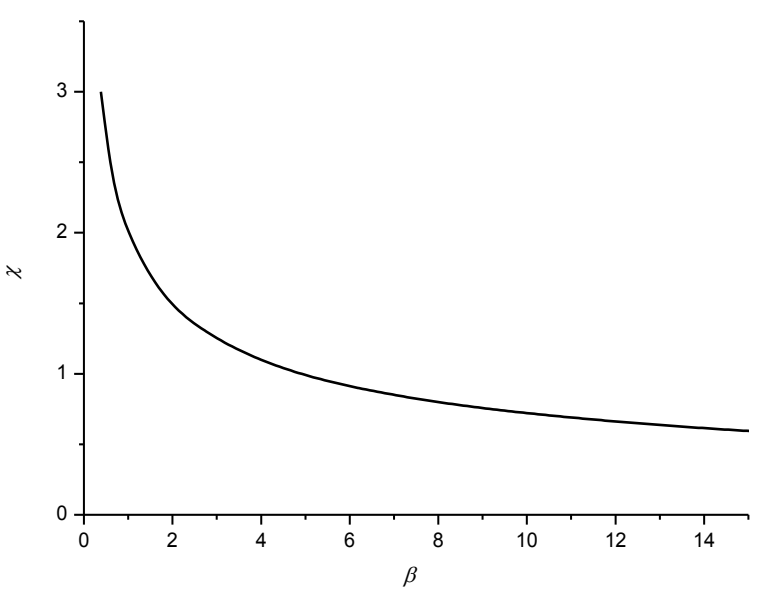

Fig. 1. Dependence $\chi(\beta)$

\section{Neutron field calculation}

Substituting (17) to (15) we obtain:

$$
\frac{D \sigma_{a}}{2 n_{0} V_{R}^{2}} \frac{r^{4}(\varphi)}{R^{4}} \frac{d \Psi^{2}}{d \varphi}=f_{1}\left(\varphi, q_{0}\right),
$$

where $f_{1}\left(\varphi, q_{0}\right)=2 \beta \varphi-\left(1-2 \beta-q_{0}\right)\left(e^{-\varphi}-1\right)+q_{0} \varphi e^{-\varphi}$.

The function $f_{1}\left(\varphi, q_{0}\right)$ has the following analytical properties [7, 8]: $f_{1}\left(0, q_{0}\right)=0, f_{1}\left(\varphi_{0}, q_{0}\right)=0$; it becomes zero at the ends of the range $0 \leq \varphi \leq \varphi_{0}$.

$$
\text { Substituting expression } \Psi=-\frac{V_{R}}{\sigma_{a}}\left(\frac{R}{r}\right)^{2} \frac{d \varphi}{d r} \text { in }
$$

equation (20) and introducing new dimensionless variables $\psi=\frac{D}{n_{0} V_{R} R} \sqrt{\frac{D}{n_{0} \sigma_{a} R^{2}}} \Psi$;

$$
\zeta=\sqrt{\left(n_{0} \sigma_{a}\right) / D} r \text {, }
$$

we get the system of equations:

$$
\begin{aligned}
& \frac{d \psi}{d \zeta}=-f_{1}(\varphi) / \zeta^{2}, \\
& \frac{d \varphi}{d \zeta}=-\psi \zeta^{2}
\end{aligned}
$$

with boundary conditions $\varphi(\infty)=0, \varphi(0)=\varphi_{0}, \psi(\infty)=0$.

Set $\varphi_{0}$ in the interval $0<\varphi_{0}<\chi$ and solve equations (21), (22) with boundary conditions (23) by the shooting method: choose a value $\psi_{0}$ and start from $\zeta=0$ with initial conditions $\varphi(0)=\varphi_{0}$ and $\psi(0)=\psi_{0}$; we obtain solutions $\varphi(\zeta)$ and $\psi(\zeta)$ diverging at $\zeta \rightarrow \infty$. We select $\psi_{0}$ so that the region of divergence was as far as possible.

Returning to the variables $r, \varphi(r)$, and $\Psi(r)$, we find the radial dependences of the neutron fluence $\varphi(r)$, and flux $\Psi(r)$, as well as the concentration profiles of plutonium

$n_{9}(r)=\sigma_{89} / \sigma_{a} n_{0} \varphi(r) e^{-\varphi(r)}$,

uranium $n_{8}(r)=n_{0} e^{-\varphi(r)}$ and fission products

$n_{c}(r)=2 \sigma_{f} \sigma_{89} / \sigma_{a}^{2} n_{0}\left[1-(1+\varphi(r)) e^{-\varphi(r)}\right]$.

We also get the expression for power:

$$
\begin{aligned}
& P=\int Q \Sigma_{f} \Psi d V= \\
& =4 \pi Q V_{R} R^{2} n_{0} \sigma_{89} \sigma_{f} / \sigma_{a}^{2}\left[1-\left(1+\varphi_{0}\right) e^{-\varphi_{0}}\right] .
\end{aligned}
$$

The speed of fuel movement is proportional to the power of the reactor. The burning wave profile remains unchanged.

The main result of theory is that spherical standingburning wave can be described with tree parameters: two combinations of nuclear cross sections $c, \beta$ and neutron fluence $\varphi_{0}$ in unloaded fuel.

Fig. 2 shows an example for radial profiles of the neutron flux in standing burning waves for material parameter $\beta=1$ (when $\chi=2-$ the maximal value of $\varphi_{0}$ ) and different values of the parameter $\varphi_{0}$.

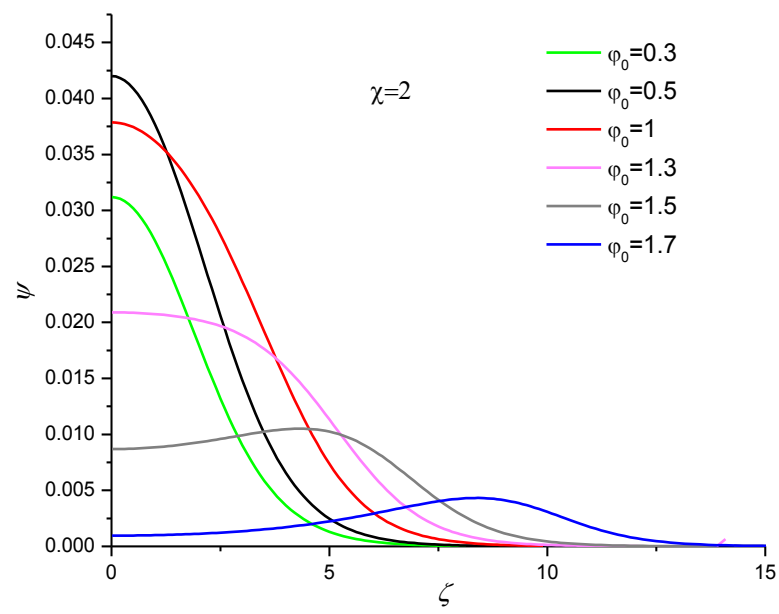

Fig. 2. Radial dependences of the neutron flux $\psi(\zeta)$ in standing waves, $\chi=2$

The maximum of neutron flux in the burning wave (see Fig. 2) moves away from the center of the core when $\varphi_{0}$ increases and goes to infinity at $\varphi_{0}=\chi$.

Fig. 3 shows dependence the power of the standing burning wave on the fluence $\varphi_{0}$ at $\chi=1$. The fundamental difference between a spherical standing-wave reactor and a one-dimension traveling-wave reactor is that its 
power can be physically limited by choosing a sufficiently small parameter $\varphi_{0}$ and small dimensions of the core. Spherical standing-wave differs from a traveling burning wave Feoktistov's type, in which the power and neutron fluxes are much more than modern structural materials can allow.

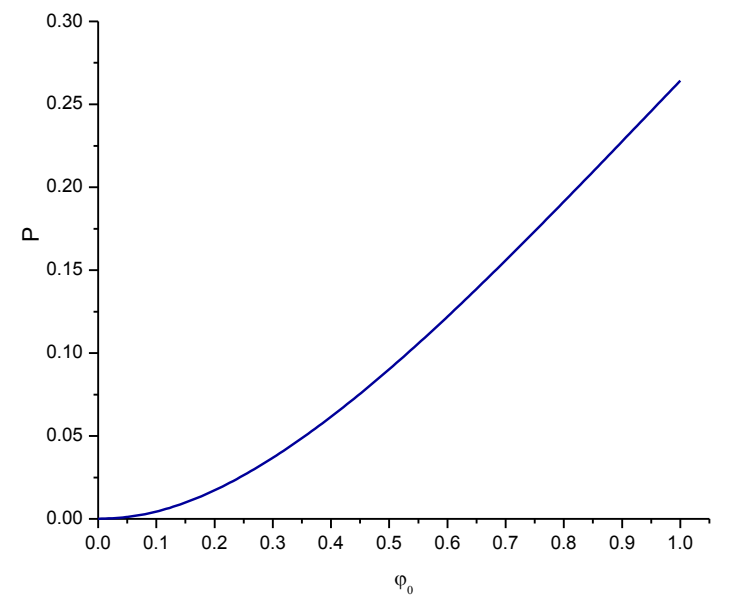

Fig. 3. Dependence of power of the standing burning wave on the fluence $\varphi_{0}$ with $\chi=1$

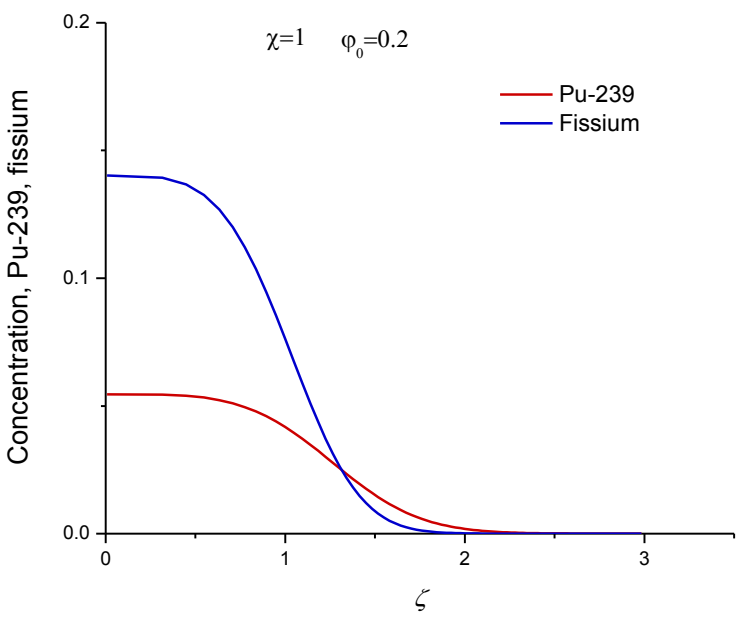

Fig. 4. Dependences of Pu-239 concentrations and fission products on the radius

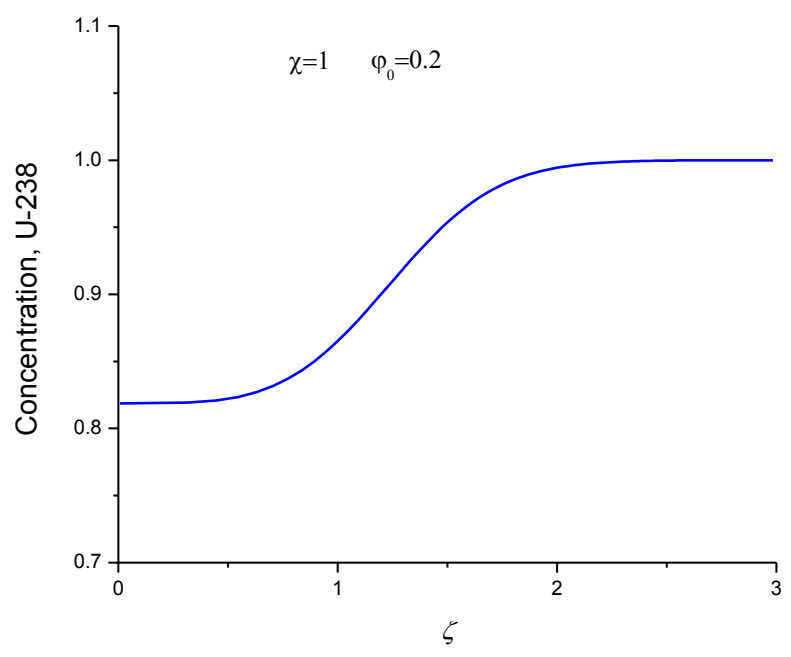

Fig. 5. Dependence of $U-238$ concentration on the radius in the standing burning wave
Figs. 4,5 show the dependences of the concentrations of $\mathrm{Pu}-239, \mathrm{U}-238$ and fission products on the radius in the standing burning wave of a spherical shape. From Fig. 5 one can see that in the standing burning wave with the specified parameters, the uranium isotope U-238 burns out by $18 \%$, and in the spent fuel there are still $\sim 6 \%$ Pu-239.

\section{ANALYSIS OF STABILITY THE SPHERICAL BURNING WAVE}

In Fig. 6 the family of phase trajectories $\psi(\varphi)$ for different values of $\varphi_{0}$ is shown.

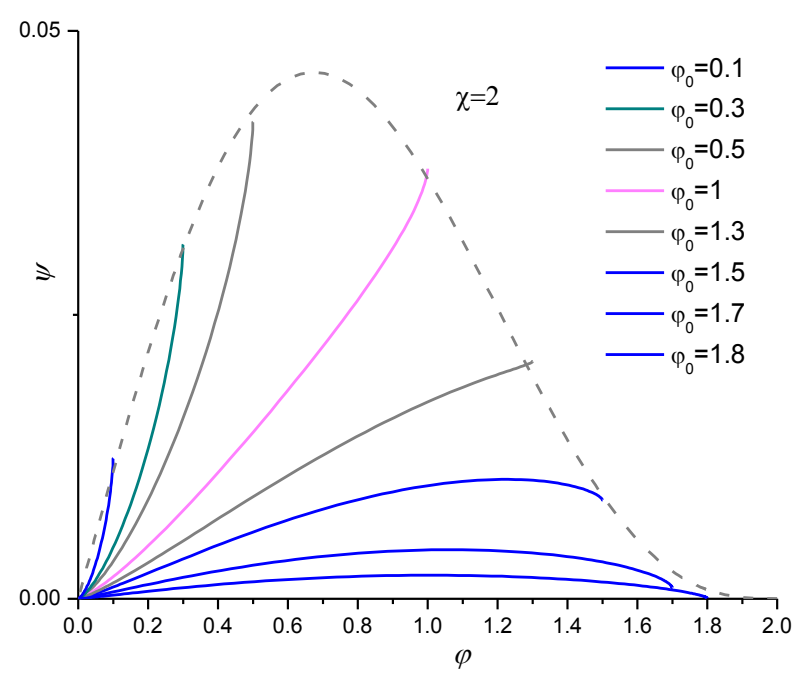

Fig. 6. Dependence $\psi(\varphi)$ for a some values of $\varphi_{0}$ at $\chi=2$

A necessary condition for stability of a standing burning wave is the positivity of the values of $\varphi$ and $\psi$ along the trajectory of the solution $\varphi(\zeta)$ and $\psi(\zeta)$. Thus, the entire trajectory of the dependence $\varphi(\psi)$ should lie in the first quadrant. As can be seen in Fig. 6 this condition is valid.

\section{Calculation of the minimum value of the parame- ter with the scope of the solution}

The condition $\rho \geq 0$ for the existence of a standing spherical wave gives a relation:

$$
c \geq q_{0}\left(\beta, \varphi_{0}\right) \text {. }
$$

Relation (27) determines $c_{\min }\left(\varphi_{0}\right)-$ the minimum value of $c$, for which a stationary solution still exists for a given value of $\varphi_{0}$. The dependence $c_{\min }\left(\varphi_{0}\right)$ has the form:

$$
c_{\min }\left(\varphi_{0}, \beta\right)=\frac{2 \beta \varphi_{0}-(1-2 \beta)\left(e^{-\varphi_{0}}-1\right)}{1-\left(1+\varphi_{0}\right) e^{-\varphi_{0}}} .
$$

The dependence $c_{\min }\left(\varphi_{0}, \beta\right)$ calculated using (28) for the value $\beta=1$ is shown in Fig. 7. The wave exists in the open region of the graph. The dependence $c_{\min }\left(\varphi_{0}, \beta\right)$ has a minimum, indicated in the graph as $c_{\mathrm{mm}}(\beta)$, which is located below the line $q(\beta)$ corresponding to a plane burning wave. One can see from Fig. 7 that a standing spherical burning wave is more stable than a plane burning wave, and two times lower fluency $\varphi_{0}$ is required for existence of a standing wave. 


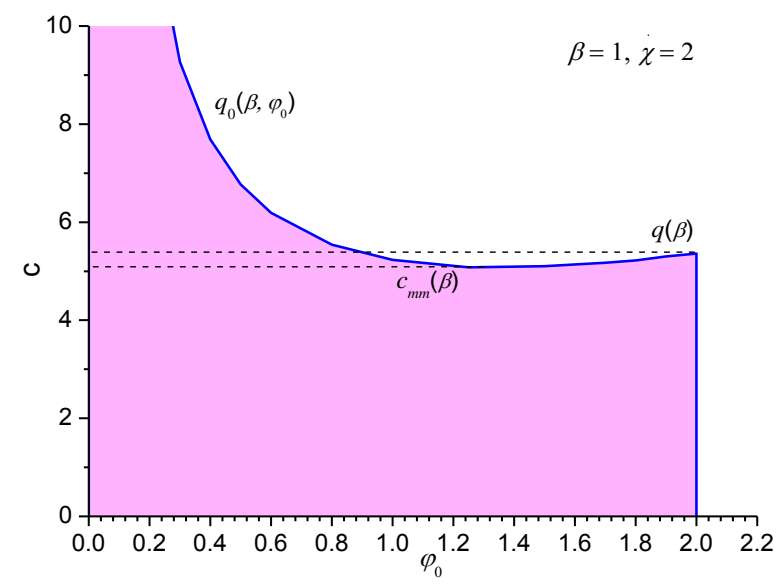

Fig. 7. Dependence of $c_{\min }\left(\varphi_{0}, \beta\right)$ on $\varphi_{0}$ with $\beta=1,(\chi=2)$

\section{State diagram of a reactor on the standing spheri- cal burning wave}

The dependence of $c_{\mathrm{mm}}(\beta)$ is shown in Fig. 8 with dotted line. It represents the lower limit of parameter $c$ for standing burning wave stability in a spherical reactor. For comparison, the lower limit of $c$ for a plane burning wave stability in an infinite medium $q(\beta)$ [4] is shown in the same graph.

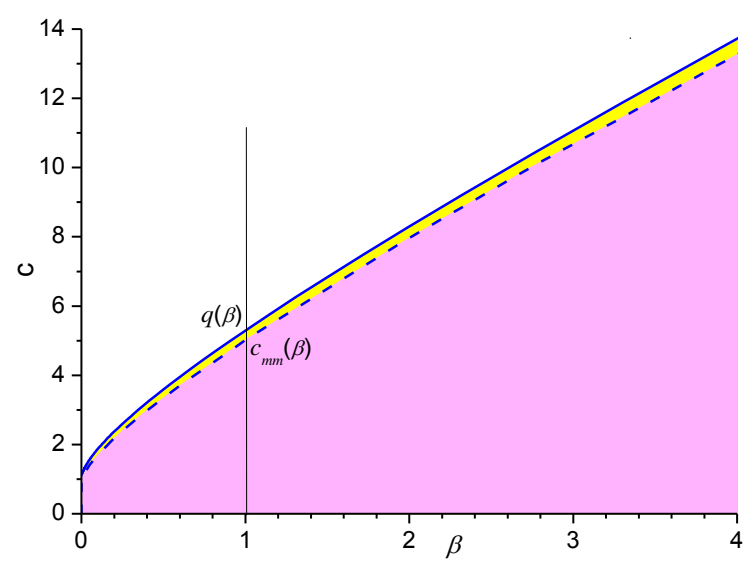

Fig. 8. State diagram of the reactor on a standing spherical burning wave

The state diagram of a reactor on a standing spherical burning wave is shown in Fig. 8. In the pink shaded region there are no standing waves, in the region shaded in yellow the spherical standing waves exist only for some values of $\varphi_{0}$. In the open region of the Fig. 8 the waves exist for any values of $\varphi_{0}$.

\section{COMPUTER SIMULATION OF SPHERICAL TRAVELLING BURNING WAVE}

Computer model of STBW is a sphere with radius $\mathrm{R}=2 \mathrm{~m}$, filled with uranium dioxide based fuel, which is divided into spherical layers with thickness of $5 \mathrm{~cm}$. In order to reach criticality an igniter containing enriched uranium was located in the central part of the reactor core. Due to transmutation under fast neutron irradiation the ${ }^{238} \mathrm{U}$ isotope converts to ${ }^{239} \mathrm{Pu}$ according to the chain: ${ }^{238} \mathrm{U}+\mathrm{n}={ }^{239} \mathrm{U} \rightarrow{ }^{239} \mathrm{~Np} \rightarrow{ }^{239} \mathrm{Pu}$. When concen- tration of ${ }^{239} \mathrm{Pu}$ in the fuel reaches high level, spherical burning wave appears; it breaks away from the central area and moves to the edges of the active zone during 30 years. In this model the speed of the burning wave is $\sim 0.5 \mathrm{~cm} /$ year at $240 \mathrm{MW}$ power (see Figs. 9 and 10 in which radial distributions of neutron flux and power are shown).

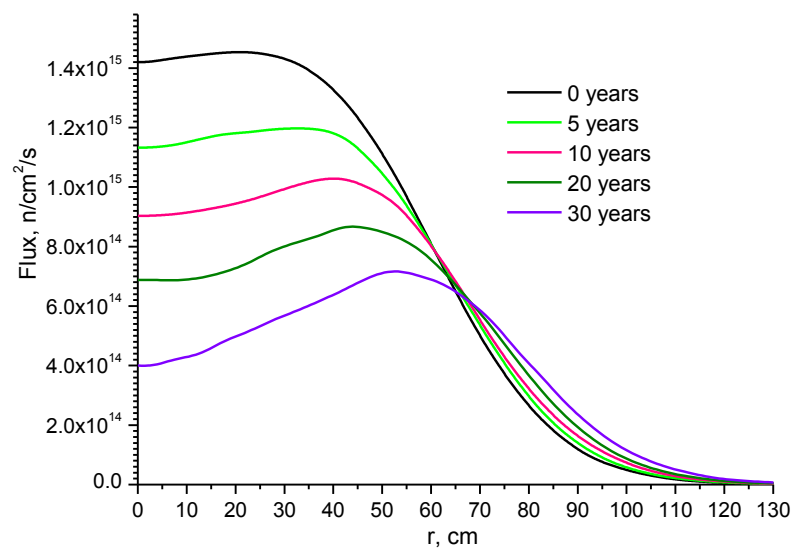

Fig. 9. Radial dependences of the neutron flux density in a traveling spherical burning wave for period of 30 years

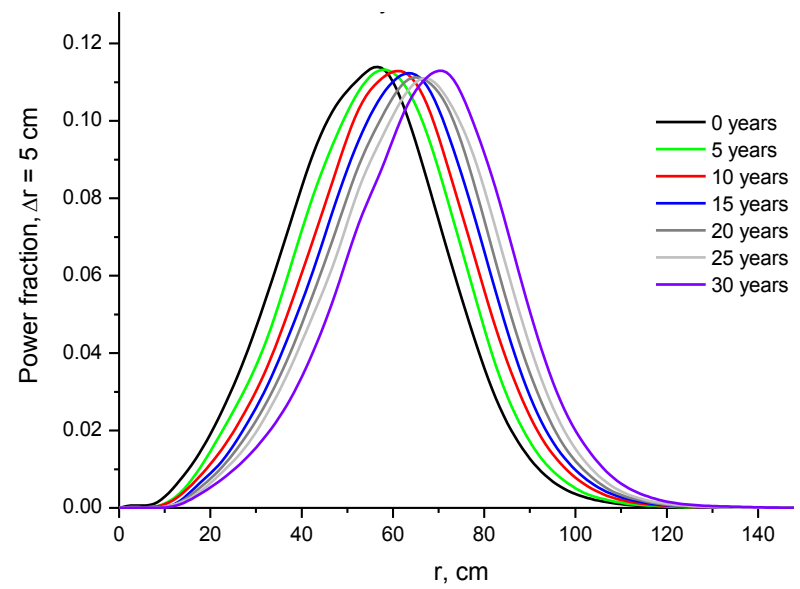

Fig. 10. Radial distribution of power fraction of the layers in the traveling spherical burning wave during 30 years at $240 \mathrm{MW}$ power

\section{COMPUTER SIMULATION OF SPHERICAL STANDING BURNING WAVE}

In SWR model fuel is moving towards the burning wave at the same speed, that ensures the stationarity of breading and burning processes in the reactor. The results of computer simulation of a standing nuclear burning wave during 20 years are shown in Fig. 11. It shows that parameters of the model ensure stationary of the spherical nuclear burning wave when reactor is fed with depleted uranium. Figs. 11-13 show dependences of power density and concentrations of Pu-239 and U-238 on the radius, which were obtained using MCNPX computer simulation of the spherical standing burning wave. They are in qualitative agreement with the theoretical results (see Figs. 3-5). 


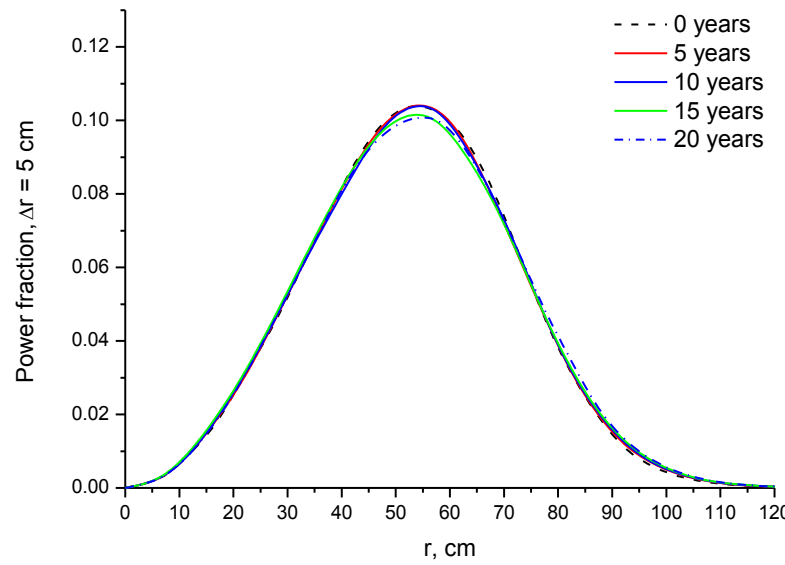

Fig. 11. Radial distribution of power fraction of the layers in a standing spherical burning wave over a period of 20 years

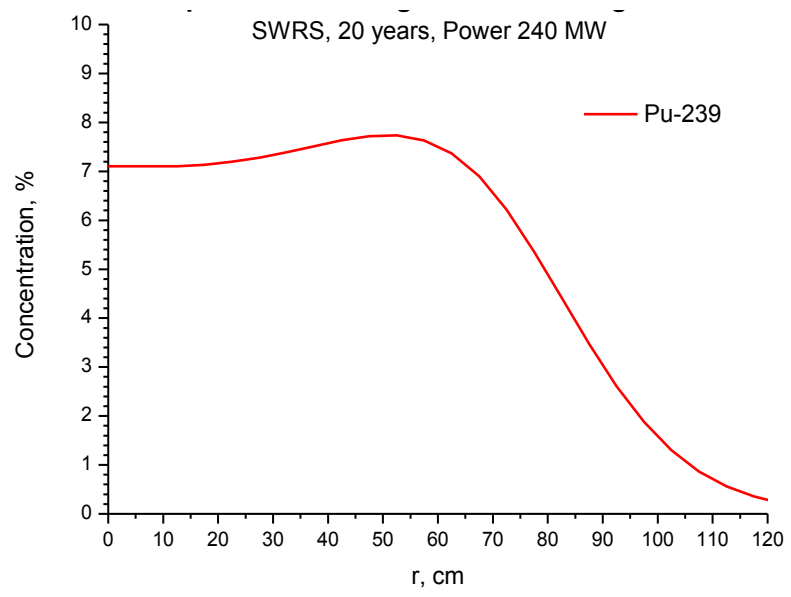

Fig. 12. Dependence of Pu-239 concentration on the radius in the standing burning wave

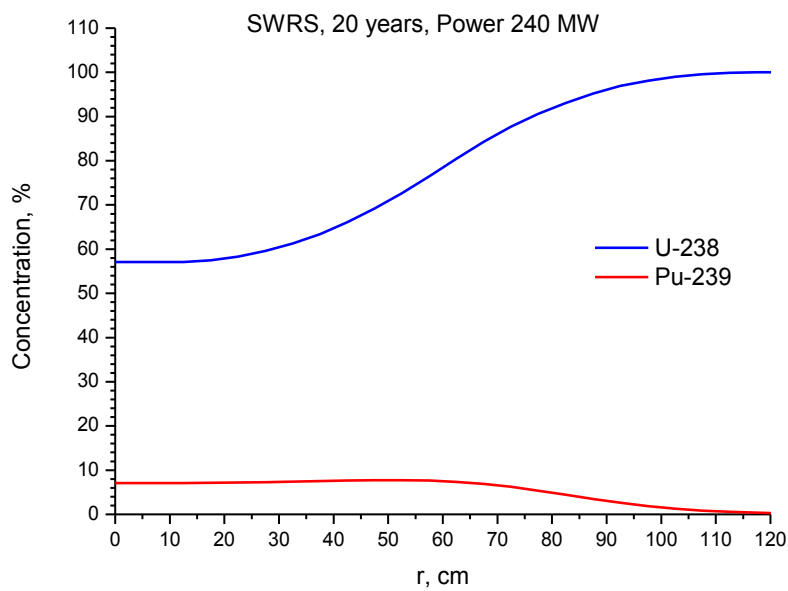

Fig. 13. Dependence of the concentrations of $U-238$ and $P u-239$ on the radius in the standing burning wave

\section{CONCLUSION}

- Standing nuclear burning wave can exist not only in one-dimensional geometry, but in systems with cylindrical and spherical symmetries as well.

- Phenomenological theory of standing spherical nuclear burning wave was developed

- Existence of a standing spherical nuclear burning wave was proved for a reactor with fuel continuously moving toward the center.

- State diagram of such a reactor was proposed and the boundaries of the standing wave existence were defined.

- Mathematical modeling of reactor on spherical standing burning wave was carried out using MCNPX code, and obtained numerical results are in agreement with results of the phenomenological theory.

\section{REFERENCES}

1. MCNPX User's Manual Version 2.5.0, April. 2005 LA-CP-05-0369

2. L.P. Feoktistov. Neutron-fission wave // Rep. Academy Sciences of the USSR. 1989, v. 309, p. 864867.

3. T. Ellis, R. Petroski. Traveling-Wave Reactors: A Truly Sustainable and Full-Scale Resource for Global Energy Needs // Proceedings of ICAPP '10, San Diego, CA, USA, June 13-17, 2010, 10189 p.

4. V.V. Gann, A.V. Gann. Benchmark on traveling wave fast reactor with negative reactivity feedback obtained with MCNPX code // 4 International Conference "Current Problems in Nuclear Physics and Atomic Energy” (NPAE-Kyiv 2012), September 3-7, 2012, Kyiv, Ukraine. Proceedings Part II, p. 421-425.

5. Yu.Y. Leleko, V.V. Gann, A.V. Gann. Computer Simulation of Stationary Burning Wave Reactor // 4th International Conference "Computer modelling in hightech” (CMHT-Kharkov 2016), May 26-31, 2016, Kharkov, Ukraine, p. 206

6. TERRAPOWER, LLC Traveling Wave Reactor Develop Program Overview //

http://dx.doi.org/10.5516/NET.02.2013.520

7. Yu.Y. Leleko, V.V. Gann, A.V. Gann. Nuclear reactor on cylindrical standing burning wave with an external negative reactivity feedback // Problems of Atomic Science and Technology. 2017, № 2(108), p. 138-143.

8. V.V.Gann, Yu.Y.Leleko, A.V.Gann Computer simulation of nuclear reactor on cylindrical standing burning wave // Proceedings of NUCLEAR 2017 the 10th International Conference on Sustainable Development through Nuclear Research and Education, Pitesti, 2017, May 24-26, p. 161-168. 


\title{
СФЕРИЧЕСКАЯ СТОЯЧАЯ ВОЛНА ЯДЕРНОГО ГОРЕНИЯ С ВНЕШНИМ АВТОМАТИЧЕСКИМ КОНТРОЛЕМ РЕАКТИВНОСТИ
}

\author{
Ю.Я. Лелеко, В.В. Ганн, А.В. Ганн
}

Была развита нейтронная кинетика стоячей волны ядерного горения в нейтронно-размножающей среде, которая не сжимается и является подвижной, при наличии ядерных реакций. Рассмотрен сферический реактор, в котором волна ядерного горения движется радиально от центра, а топливо - в центр реактора. Показано, что при подпитке такой системы ${ }^{238} \mathrm{U}$ в ней может существовать сферическая стоячая волна ядерного горения. Проведено сравнение теоретических результатов с данными численного моделирования такого реактора с использованием кода MCNPX.

\section{СФЕРИЧНА СТОЯЧА ХВИЛЯ ЯДЕРНОГО ГОРІННЯ 3 ЗОВНІШНІМ АВТОМАТИЧНИМ КОНТРОЛЕМ РЕАКТИВНОСТІ}

\section{Ю.Я. Лелеко, В.В. Ганн, А.В. Ганн}

Була розвинена нейтронна кінетика стоячої хвилі ядерного горіння в нейтронно-розмножуючім середовищі, котре не стискається та є рухомим, при наявності ядерних реакцій. Розглянуто сферичний реактор, в якому хвиля ядерного горіння рухається радіально від центра, а паливо - до центра реактора. Показано, що при підживленні такої системи ${ }^{238} \mathrm{U}$ в ній може існувати сферична стояча хвиля ядерного горіння. Проведено порівняння теоретичних результатів 3 даними чисельного моделювання такого реактора 3 використанням коду MCNPX. 